\title{
Enlarged subcutaneous abdominal adipocyte size, but not obesity itself, predicts Type II diabetes independent of insulin resistance
}

\author{
C. Weyer, J. E. Foley, C. Bogardus, P. A. Tataranni, R. E. Pratley \\ Clinical Diabetes and Nutrition Section, National Institute of Diabetes and Digestive and Kidney Diseases, \\ National Institutes of Health, \\ Phoenix, Arizona, USA
}

\section{Abstract}

Aims/hypothesis. Cross-sectional studies indicate that enlarged subcutaneous abdominal adipocyte size is associated with hyperinsulinaemia, insulin resistance and glucose intolerance. To further explore the pathophysiological significance of these associations, we examined prospectively whether enlarged subcutaneous abdominal adipocyte size predicts Type II (non-insulin-dependent) diabetes mellitus.

Methods. Body composition (hydrodensitometry), mean subcutaneous abdominal adipocyte size (fat biopsy), insulin sensitivity (hyperinsulinaemic clamp) and the acute insulin secretory response (25-g i.v. GTT) were assessed in 280 Pima Indians with either normal (NGT), impaired (IGT) or diabetic glucose tolerance (75-g OGTT). Subjects with NGT were then followed prospectively.

Results. After adjusting for age, sex and per cent body fat, mean subcutaneous abdominal adipocyte size was $19 \%$ and $11 \%$ higher in subjects with diabetes and IGT, compared with those with NGT $(p<0.001)$. Insulin sensitivity was inversely corre- lated with mean subcutaneous abdominal adipocyte size $(r=-0.53, p<0.0001)$, even after adjusting for per cent body fat $(r=-0.31, p<0.001)$. In 108 NGT subjects followed over $9.3 \pm 4.1$ years (33 of whom developed diabetes), enlarged mean subcutaneous abdominal adipocyte size but not high per cent body fat, was an independent predictor of diabetes, in addition to a low insulin sensitivity and acute insulin secretory response [relative hazard $10^{\text {th }}$ vs $90^{\text {th }}$ centile (95\% CI): 5.8 (1.7-19.6), $p<0.005]$. In 28 NGT subjects with a $9 \%$ weight gain over $2.7 \pm 1.3$ years, changes in insulin sensitivity were inversely and independently related to changes in mean subcutaneous abdominal adipocyte size and per cent body fat.

Conclusion/interpretation. Although enlarged mean subcutaneous abdominal adipocyte size is associated with insulin resistance cross-sectionally, prospectively, both abnormalities are independent and additive predictors of Type II diabetes. [Diabetologia (2000) 43: 1498-1506]

Keywords Obesity, adipose tissue, glucose intolerance, predictors, prospective study.
Received: 31 July 2000 and in revised form: 6 September 2000

Corresponding author: C. Weyer, MD, Clinical Diabetes and Nutrition Section, National Institutes of Health, $4212{\mathrm{~N} 16^{\text {th }}}$ Street. Rm. 5-41, Phoenix, AZ 85016, USA

Abbreviations: AIR, acute insulin response; s.c. abd. AS, subcutaneous abdominal adipocyte size; EMBS, estimated metabolic body size; $\mathrm{GH}$, growth hormone; $\mathrm{M}$, insulin-stimulated glucose disposal; PPAR $\gamma$, peroxisome proliferator-activated receptor; WHO, World health Organisation; ADA, American Diabetes Association; WTR, waist-to-thigh ratio.
Epidemiological studies have firmly established that obesity is a major risk factor for the development of Type II (non-insulin-dependent) diabetes mellitus [1-4]. Obesity does not, however, invariably result in diabetes and many people who are very obese are able to maintain normal glucose tolerance. The reason why some people with obesity develop Type II diabetes and others do not is largely not known.

There is good evidence that differences in body fat distribution play a part [3-9]. A large number of cross-sectional studies have shown that obese people with an abdominal pattern of fat accumulation are 
more likely to have prediabetic abnormalities such as insulin resistance, hyperinsulinaemia and glucose intolerance than those with a more femoro-gluteal pattern [6-9]. In prospective studies, abdominal fat distribution and obesity were independent and additive risk factors for diabetes [3-5]. Differences in body fat distribution alone, however, are unlikely to be the only explanation for differences in the propensity to diabetes among people with obesity.

Differences in adipose tissue cellularity have also been implicated as a possible link between obesity and diabetes. More than three decades ago, it was found that obese people with enlarged subcutaneous abdominal adipocyte size (s. c. abd. AS) are, on average, more hyperinsulinaemic and glucose intolerant than those with a similar degree of adiposity but with relatively smaller s.c. abd. AS [8-14]. These findings led some authors to hypothesize that people who become obese primarily through an increase in fat cell size ("hypertrophic obesity") are more likely to develop obesity-related metabolic disturbances (insulin resistance, hyperinsulinaemia and diabetes) than those in whom the increase in adiposity is primarily mediated by an increase in fat cell number ("hyperplastic obesity") $[9,10]$.

The recent findings that both the pharmacological activation [15] and partial genetic disruption [16] of the adipogenic transcription factor peroxisome proliferator-activated receptor (PPAR $\gamma$ ) improves insulin sensitivity in parallel with a reduction in mean s.c. adipocyte size in rodents, has sparked renewed interest in the association between adipocyte size and glucose homeostasis. This has been further promoted by a growing number of reports of enlarged s. c. adipocytes in several physiological and pathological conditions typically associated with insulin resistance and glucose intolerance such as puberty [17-19], pregnancy [20, 21] and older age [22, 23] as well as growth hormone $(\mathrm{GH})$ deficiency $[24,25]$, polycystic ovary syndrome [26], and Type II diabetes $[27,28]$.

Interpretation of these findings, however, is hampered by cross-sectional studies, by design, not being able to resolve whether the presence of enlarged s.c. abd. adipocytes predicts the development of diabetes or is simply a consequence of insulin resistance, hyperinsulinaemia or glycaemic deterioration.

In the present series of studies, we addressed this question by analysing cross-sectional, prospective, and longitudinal data from a large number of Pima Indians, a population with a high propensity for obesity and Type II diabetes [2], who were comprehensively characterized for body composition, body fat distribution, mean s.c. abd. AS, glucose tolerance, insulin sensitivity and insulin secretion.

\section{Subjects and methods}

Subjects. Subjects in this study were participants in an ongoing longitudinal study of the pathogenesis of Type II diabetes initiated by the National Institutes of Health (NIH) in 1982 [5, 29, 30]. All participants were Pima (or closely related Tohono O'Odham) Indians from the Gila River Indian Community near Phoenix, Arizona in the United States. Between 1982 and 1990, 280 subjects $\{172$ with normal (NGT), 79 with impaired (IGT) and 29 with diabetic glucose tolerance [according to World Health Organisation (WHO) diagnostic criteria [31], Table 1]\} were admitted for 8-15 days to the NIH Clinical Research Unit in Phoenix. After at least 3 days on a weight maintaining diet, a series of tests were conducted that included the assessment of body composition (hydrodensitometry), body fat distribution (waist-to-thigh circumference ratio), mean s.c. abd. AS (fat biopsy), glucose tolerance (75-g OGTT), insulin sensitivity (hyperinsulinaemic clamp) and early phase insulin secretion (25-g intravenous GTT) (see below). Subjects were then invited back at approximately annual intervals for repeat OGTTs (allowing for prospective analyses) and, in a subgroup of subjects, also for repeat fat biopsies and hyperinsulinaemic clamps (allowing for longitudinal analyses). Except for Type II diabetes in 29 subjects (as diagnosed by applying both the WHO [31] and American Diabetes Association (ADA) [32] diagnostic criteria), all study participants were healthy according to a comprehensive medical history, physical examination and routine blood and laboratory tests and none smoked or took medications at the time of the study. The study protocol was approved by the Institutional Review Board of the National Institutes of Diabetes and Digestive and Kidney Diseases and by the Tribal Council of the Gila River Indian Community. All subjects gave written informed consent before participation.

In a first, cross-sectional analysis, we used the baseline data from the entire group of 280 subjects to examine the relations among per cent body fat, body fat distribution, mean s. c. abd. AS, fasting plasma NEFA and insulin concentrations, insulin sensitivity, and glucose tolerance.

In a second prospective analysis, we used follow-up data on 108 subjects who were all NGT at baseline and had either developed diabetes (progressors, $n=33$ ) or remained NGT (nonprogressors, $n=75$ ) over an average of $9.3 \pm 4.1$ years (Table 1). The aim of this analysis was to examine whether enlarged mean s. c. abd. AS predicts the development of Type II diabetes.

Finally, in a longitudinal analysis, we used follow-up data from all subjects $(n=28)$ in our study who met the following criteria: (1) NGT at baseline and non-diabetic (NGT or IGT) at follow-up, (2) an increase in body weight and fat mass, (3) a repeat hyperinsulinaemic clamp and fat biopsy at follow-up and (4) a minimum follow-up duration of 0.5 years (average $2.7 \pm 1.3$ years). The aim of this analysis was to examine how changes in mean s.c. abd. AS in response to long-term weight gain relate to concomitant changes in adiposity, insulin sensitivity and glucose tolerance.

Anthropometric measurements. Body composition was estimated by underwater weighing with simultaneous measurement of residual lung volume by helium dilution and per cent body fat, fat mass and fat-free mass were calculated as described previously $[29,30]$. Waist and thigh circumferences were measured at the umbilicus and the gluteal fold in the supine and standing position, respectively and the waist-to-thigh ratio (WTR) was calculated as an index of body fat distribution.

Fat biopsy and in vitro characterization of adipocytes. The procedures for fat biopsies and assessment of adipocyte size and lipolytic activity have been described in detail previously 
Table 1. Physical and metabolic characteristics of the subjects in the different analyses (means \pm SD)

\begin{tabular}{|c|c|c|c|c|c|c|c|}
\hline & \multicolumn{3}{|c|}{ Cross-sectional analysis } & \multicolumn{2}{|c|}{ Prospective analysis } & \multicolumn{2}{|c|}{ Longitudinal analysis } \\
\hline & NGT & IGT & diabetes & non-progr. & progressors & baseline & follow-up \\
\hline$n$ (women/men) & $172(68 / 104)$ & $79(51 / 28)$ & $29(20 / 9)$ & $75(50 / 25)$ & $33(14 / 19)$ & $28(11 / 17)$ & \\
\hline height $(\mathrm{cm})$ & $166 \pm 8^{a}$ & $163 \pm 7^{\mathrm{a}}$ & $161 \pm 9^{a}$ & $166 \pm 8$ & $165 \pm 8$ & $165 \pm 8$ & $165 \pm 8$ \\
\hline body weight (kg) & $94.0 \pm 25.3^{\mathrm{a}}$ & $98.9 \pm 22.4^{b}$ & $96.4 \pm 15.4^{\mathrm{a}, \mathrm{b}}$ & $94.6 \pm 23.9$ & $100.1 \pm 17.0$ & $92.7 \pm 19.2$ & $100.4 \pm 22.0^{\mathrm{f}}$ \\
\hline body fat $(\%)$ & $32 \pm 9^{a}$ & $36 \pm 8^{a}$ & $37 \pm 6^{\mathrm{a}}$ & $32 \pm 8$ & $36 \pm 7$ & $32 \pm 7$ & $36 \pm 7^{f}$ \\
\hline waist-to-thigh ratio & $1.61 \pm 0.17^{\mathrm{a}}$ & $1.68 \pm 0.14^{\mathrm{b}}$ & $1.76 \pm 0.16^{\mathrm{c}}$ & $1.62 \pm 0.14$ & $1.64 \pm 0.17$ & $1.61 \pm 0.14$ & $1.66 \pm 0.18^{\mathrm{d}}$ \\
\hline fasting glucose $(\mathrm{mmol} / \mathrm{l})$ & $5.1 \pm 0.4^{\mathrm{a}}$ & $5.4 \pm 0.5^{\mathrm{b}}$ & $9.0 \pm 3.6^{\mathrm{c}}$ & $5.2 \pm 0.3$ & $5.4 \pm 0.3$ & $5.2 \pm 0.4$ & $5.3 \pm 0.4$ \\
\hline 2 -h glucose $(\mathrm{mmol} / \mathrm{l})$ & $6.3 \pm 0.9^{\mathrm{a}}$ & $9.2 \pm 0.9^{b}$ & $16.6 \pm 4.8^{\mathrm{c}}$ & $6.3 \pm 1.0$ & $6.8 \pm 0.7$ & $6.6 \pm 1.0$ & $6.9 \pm 1.4$ \\
\hline fasting NEFA $(\mu \mathrm{mol} / \mathrm{l})$ & $339 \pm 86^{\mathrm{a}}$ & $386 \pm 106^{\mathrm{b}}$ & $446 \pm 103^{c}$ & $345 \pm 97$ & $359 \pm 119$ & $360 \pm 87$ & $333 \pm 83$ \\
\hline fasting insulin $(\mathrm{pmol} / \mathrm{l})$ & $198 \pm 96^{\mathrm{a}}$ & $288 \pm 102^{b}$ & $324 \pm 138^{b}$ & $198 \pm 90$ & $258 \pm 120^{\mathrm{e}}$ & $204 \pm 72$ & $246 \pm 102^{\mathrm{e}}$ \\
\hline $\mathrm{M}\left(\mathrm{mg} \cdot \mathrm{kg} \mathrm{EMBS}-1 \cdot \mathrm{min}^{-1}\right)^{\mathrm{g}}$ & $2.8 \pm 0.9^{\mathrm{a}}$ & $2.1 \pm 0.4^{\mathrm{b}}$ & $1.9 \pm 0.2^{\mathrm{c}}$ & $2.7 \pm 0.8$ & $2.3 \pm 0.8^{\mathrm{e}}$ & $2.4 \pm 0.5$ & $2.2 \pm 0.4^{\mathrm{e}}$ \\
\hline $\operatorname{AIR}(\mathrm{pmol} / \mathrm{l})^{\mathrm{g}}$ & $1548 \pm 1134^{\mathrm{a}}$ & $1284 \pm 714^{\mathrm{a}}$ & $462 \pm 684^{b}$ & $1470 \pm 858$ & $1284 \pm 804$ & $1692 \pm 972$ & $1446 \pm 936$ \\
\hline
\end{tabular}

Cross-sectional analysis: values not sharing a common charac- $\quad{ }^{\mathrm{d}} p<0.05,{ }^{\mathrm{e}} p<0.01,{ }^{\mathrm{f}} p<0.001$. In prospective analysis diffeter $(\mathrm{a}, \mathrm{b}, \mathrm{c})$ are significantly different. na, not assessed. sterisks indicate significant changes over time rences between non-progressors and progressors at baseline and in longitudinal analysis change over time

All comparisons adjusted for age and sex, ${ }^{\mathrm{g}}$ additionally adjusted for per cent body fat

[33-36]. In brief, s. c. abd. adipose tissue was removed from the periumbilical region by either a surgical procedure or percutaneous needle biopsy. Immediately following the biopsy, fat specimens were fixed in $2 \%$ osmoic acid for $48 \mathrm{~h}$ and then used to prepare a suspension of adipocytes in normal saline. Adipocyte size was measured electronically using a Coulter channelizer (model 2B, Coulter Electronics Inc, Hialeah, Fla., USA) with a $400-\mu \mathrm{m}$ aperture equipped with a logarithmic scale expander. The volume of cells in the 100 channels was calculated from a known volume in a reference channel. The average volume of cells in the channels was then divided by the total number of cells sized. Cell volume was converted to $\mu \mathrm{g}$ lipid/cell using a correction factor of $0.91 \mu \mathrm{g}$ lipid/nl cell volume [36]. Basal and isoproterenol-stimulated lipolysis of the isolated adipocytes were assessed as previously described [34].

Oral glucose tolerance test. After an overnight fast, subjects underwent a 75-g oral glucose tolerance test [31]. Plasma samples were drawn at baseline and after $2 \mathrm{~h}$ for measurement of plasma glucose and insulin concentrations. Glucose tolerance was classified according to the 1985 WHO diagnostic criteria [31] in use at the time the baseline studies were undertaken. The results presented in the following were, however, similar when the 1997 ADA diagnostic criteria [32] were applied.

Hyperinsulinaemic euglycaemic clamp. Insulin sensitivity was assessed by a hyperinsulinaemic euglycaemic glucose clamp as previously described $[5,29,30]$. In brief, after an overnight fast, a primed continuous intravenous insulin infusion was given for $100 \mathrm{~min}$ at a constant rate of $40 \mathrm{mU}$ per square metre body surface area per min leading to a steady-state plasma insulin concentration of $840 \pm 252 \mathrm{pmol} / \mathrm{l}$ (means \pm SD). Plasma glucose concentrations were maintained at approximately $5.5 \mathrm{mmol} / \mathrm{l}$ with a variable infusion of a $20 \%$ glucose solution. From the rate of glucose infused during the last $40 \mathrm{~min}$ of the clamp and the rate of endogenous glucose output [measured by a primed $(1.1 \mathrm{MBq})$, continuous $\left(0.11 \mathrm{MBq}\right.$ per min) $3-{ }^{3} \mathrm{H}-$ glucose infusion], the rate of total insulin-stimulated glucose disposal (M) was calculated and normalized to estimated metabolic body size $(\mathrm{EMBS}=$ fat-free mass $+17.7 \mathrm{~kg})$ as described $[5,29,30]$.
Intravenous glucose tolerance test. Early phase insulin secretion was measured in response to a 25 -g intravenous glucose bolus with calculation of the acute insulin response (AIR) as the average incremental plasma insulin concentration from the $3 \mathrm{rd}$ to the 5 th minute after the glucose bolus $[5,29,30]$.

Analytic procedures. Plasma glucose concentrations were measured by the glucose oxidase method (Beckman Instruments, Fullerton, Calif., USA). Plasma insulin concentrations were measured by radioimmunoassay, using either the Herbert modification of the method of Yalow and Berson or an automated analyzer (Concept 4, ICN, Costa Mesa, Calif., USA) $[5,30,31]$. Fasting plasma NEFA concentrations were measured using the method of Miles [37]. The mean fasting plasma glucose and insulin concentration was calculated as the average of three fasting glucose and insulin concentrations assessed on separate days during the same admission.

\section{Statistical analyses}

Statistical analyses were done using the procedures of the SAS Institute (Cary, N. C., USA). Results are given as means \pm SD. A $p$ value of less than 0.05 was considered statistically significant. General linear regression models with simultaneous adjustment for age and sex were used to compare baseline characteristics between subjects with NGT, IGT and diabetes, and between progressors and non-progressors.

Cross-sectional analysis. Simple linear regression models with calculation of the Pearson correlation coefficient were used to examine the relation between selected variables. Stepwise and general linear regression models were used to examine the relation between selected variables after adjustment for co-variates and to generate the residuals of mean s.c. abd. AS after adjustment for age, sex and per cent body fat (using a square term of per cent body fat to account for the curvilinear relation with mean s.c. abd. AS).

Prospective analysis. Risk factors for diabetes were estimated by multivariate Cox proportional hazards analysis $[5,30]$. The 

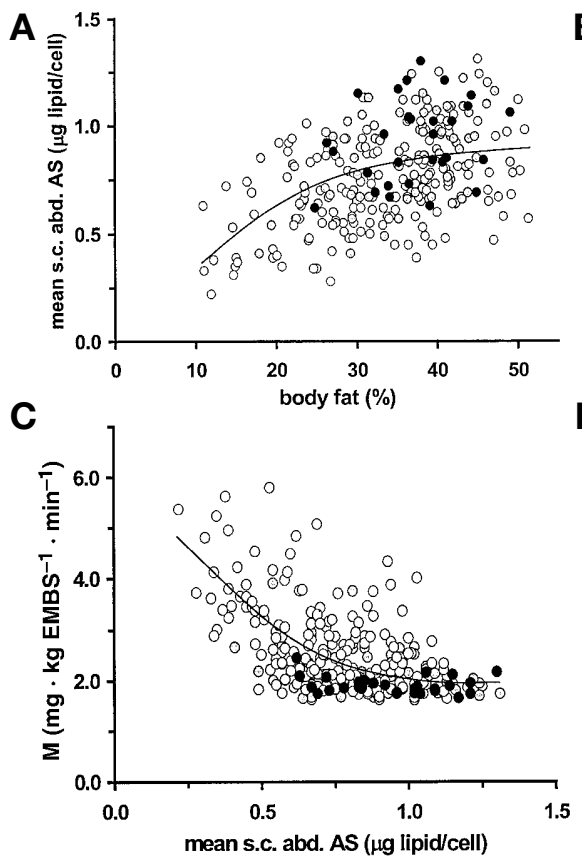

Fig. 1A-D. Cross-sectional and prospective analysis. A Relation between mean s.c. abd. AS and per cent body fat in 280 Pima Indians with either NGT $(n=172,0)$, IGT $(n=79,0)$ or diabetes $(n=29,0) r=0.45, p<0.0001$. B Mean s.c. abd. AS in subjects with NGT, IGT or diabetes (least square mean, adjusted for age, sex and per cent body fat). ** $p<0.01 * * *$ $p<0.001$ vs NGT. C Relation between insulin-stimulated glucose disposal (M) and mean s.c. abd. AS. $r=-0.53$, $p<0.0001$. D 7-year cumulative incidence of Type II diabetes in 108 Pima Indians with initially NGT as a function of their baseline mean s.c. abd. AS and insulin sensitivity (M) (divided by the respective medians)

predictive effect of a given variable after adjusting for all other variables included in the model was expressed as a relative hazard and was evaluated for the $10^{\text {th }}$ and $90^{\text {th }}$ centiles. Accordingly, the relative hazard for a given predictor variable estimates the hazard of a hypothetical subject at the $90^{\text {th }}$ centile compared with the hazard of a hypothetical subject at the $10^{\text {th }}$ centile. For each relative hazard, the $95 \%$ confidence interval is given.

Longitudinal analysis. The changes $(\Delta)$ in mean s.c. abd. AS, per cent body fat, $M$ and in other anthropometric and metabolic variables were tested for statistical significance using paired $t$ tests and correlated with one another using simple and multiple regression models.

\section{Results}

The anthropometric and metabolic characteristics of the subjects in the different analyses are shown in Table 1.

Cross-sectional analysis. There was a positive curvilinear relation between the mean s.c. abd. AS and
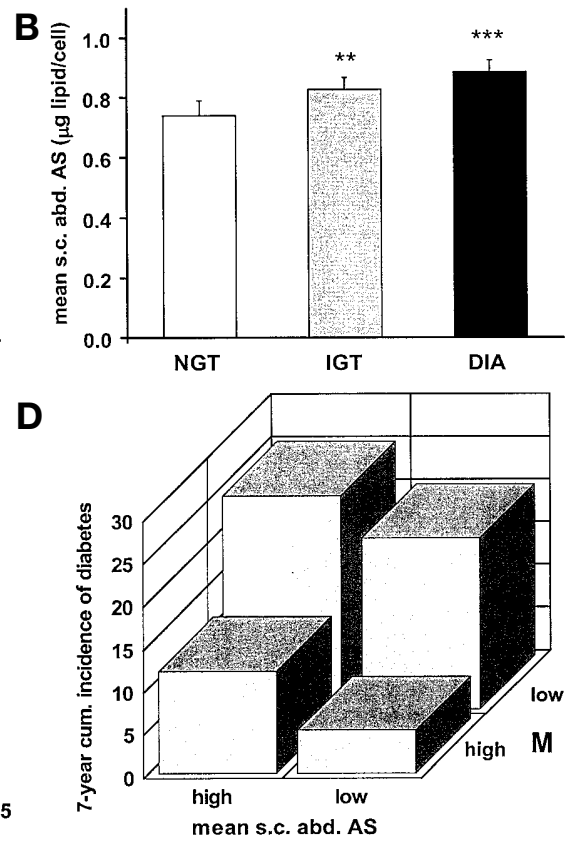

per cent body fat (Fig.1). At any given degree of adiposity, there was, however, considerable interindividual variability in mean s.c. abd. AS, with some subjects having relatively large (above the regression line, positive residuals) and others having relatively small (below the regression line, negative residuals) s. c. abd. adipocytes. Mean s. c. abd. AS was higher in subjects with IGT and diabetes than those with NGT (Table 1), differences that remained significant after adjustment for per cent body fat (Fig. 1). The rate of insulin-stimulated glucose disposal (M) was negatively correlated with mean s.c. abd. AS, basal adipocyte lipolysis and per cent body fat (Fig. 1, Table 2). The $M$ remained negatively correlated with mean s.c. abd. AS after adjustment of the latter for basal adipocyte lipolysis or per cent body fat (both $r=-0.31$, $p<0.001)$. Similar results were obtained when subjects with IGT and diabetes were excluded from the analysis (Table 2).

Prospective analysis. Compared with subjects who remained NGT, subjects who subsequently developed diabetes had not only lower M and lower AIR, but also $16 \%$ larger mean s.c. abd. AS at baseline, when they still had NGT (Table 1). Although M and mean s. c. abd. AS were negatively related with one another (see above), in a multivariate Cox proportional hazards analysis, large mean s.c. abd. AS and low M were significant independent predictors of diabetes, in addition to low AIR (Table 3, Fig. 1). Accordingly, after adjustment for age, sex, per cent body fat, M and AIR, a subject with a mean s.c. abd. AS at the upper $90^{\text {th }}$ centile $(1.08 \mu \mathrm{g}$ lipid/cell) had a 5.8 -fold higher risk of developing diabetes than one with a mean s.c. abd. AS at the lower $10^{\text {th }}$ centile $(0.55 \mu \mathrm{g}$ lipid/cell) (Table 3). When subjects were divided by 
Table 2. Relations among different measures of adiposity and selected metabolic variables

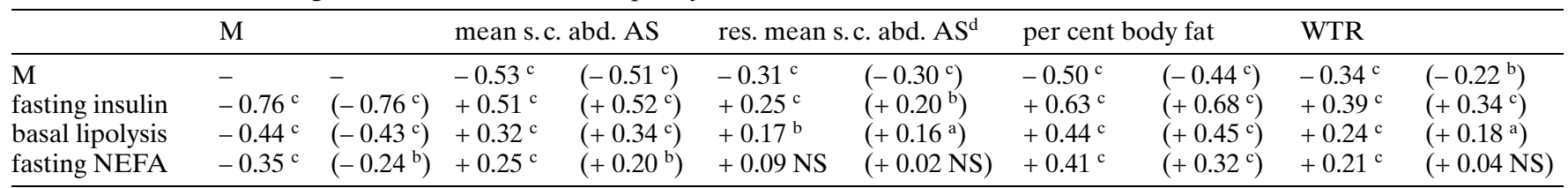

Pearson correlation coefficients as assessed in the entire study cohort $(n=280)$ and in subjects with NGT only $(n=172$, in brackets).
${ }^{\mathrm{a}} p<0.05,{ }^{\mathrm{b}} p<0.01,{ }^{\mathrm{c}} p<0.001$, NS, not significant).

${ }^{\mathrm{d}}$ residual mean s. c. abd. AS (adjusted for age, sex and percent body fat)

Table 3. Multivariate Cox proportional hazard analysis of predictors of Type II diabetes in 108 normal glucose tolerant Pima Indians followed for $9.3 \pm 4.1$ years

\begin{tabular}{|c|c|c|c|c|c|}
\hline \multirow[t]{2}{*}{ Predictor variable } & \multicolumn{2}{|l|}{ value at } & \multirow[t]{2}{*}{ relative hazard ${ }^{a}$} & \multirow[t]{2}{*}{$95 \% \mathrm{CI}$} & \multirow[t]{2}{*}{$p$-value } \\
\hline & $10^{\text {th }}$ centile & $90^{\text {th }}$ centile & & & \\
\hline sex & & & 0.9 & $0.4-2.7$ & 0.95 \\
\hline body fat (\%) & 23 & 43 & 1.0 & $0.9-1.1$ & 0.92 \\
\hline mean s.c. abd. AS ( $\mu$ g lipid/cell) & 0.55 & 1.08 & 5.8 & $1.7-19.6$ & $<0.005$ \\
\hline $\mathrm{M}\left(\mathrm{mg} \cdot \mathrm{kg} \mathrm{EMBS}^{-1} \cdot \mathrm{min}^{-1}\right)^{\mathrm{b}}$ & 1.8 & 3.7 & 6.0 & $1.7-21.3$ & $<0.007$ \\
\hline $\operatorname{AIR}(\mathrm{pmol} / \mathrm{l})^{\mathrm{b}}$ & 564 & 2556 & 3.8 & $1.3-10.9$ & $<0.02$ \\
\hline
\end{tabular}

${ }^{a}$ Hazard rate for a hypothetical subject at the centile with the higher risk of diabetes divided by the hazard rate for a hypo-

${ }^{\mathrm{b}}$ For $\mathrm{M}$ and AIR, the value at the $90^{\text {th }}$ centile is the value associated with the lower risk for diabetes.

thetical subject at the centile with the lower risk

the medians of $\mathrm{M}$ and mean s.c. abd. AS at baseline, those with $\mathrm{M}$ below and mean s.c. abd. AS above the median had the highest 7-year cumulative incidence of diabetes and those with $\mathrm{M}$ above and mean s.c. abd. AS below the median had the lowest incidence (Fig. 1, model adjusted for age, sex, per cent body fat and AIR). Subjects with both $M$ and mean s. c. abd. AS above or below the median had an intermediate risk of developing diabetes (Fig.1). Unlike mean s.c. abd. AS, neither per cent body fat, WTR, basal adipocyte lipolysis nor fasting plasma NEFA, glucose, or insulin concentrations were predictive of diabetes after adjustment for age, sex, M and AIR.

Longitudinal analysis. In the 28 subjects with initial NGT, an average weight gain of $7.7 \mathrm{~kg}$ over $2.7 \pm 1.3$ years was associated with a $4 \%$ increase in body fat, a $14 \%$ increase in mean s.c. abd. AS and an $8 \%$ decrease in $\mathrm{M}$ (all $p<0.01$, Table 1$)$. The change in $\mathrm{M}$ was inversely correlated with the changes in per cent body fat and in mean s.c. abd. AS (Fig. 2). The $\Delta$ percent body fat and $\Delta$ mean s.c. abd. AS were not, however, related with one another (Fig.2) and were independent determinants of $\Delta \mathrm{M}$ in a multivariate analysis. At follow-up, 8 of the 28 subjects ( 6 women and 2 men) had transitioned from NGT to IGT. Compared with the 20 subjects who remained NGT, these subjects had similar per cent body fat and 2-h glucose concentration at baseline but, in accordance with the results of our prospective analysis, had lower M (2.2 vs $2.5 \mathrm{mg} \cdot \mathrm{kg} \mathrm{EMBS}^{-1}$. $\left.\min ^{-1}, p<0.05\right)$ and larger mean s.c. abd. AS (Fig. 2) at baseline. In response to a similar weight gain over a similar time period $(+9.4 \pm 8.6 \mathrm{~kg}$ over $2.6 \pm 0.9$ years vs $+7.0 \pm 6.7 \mathrm{~kg}$ over $2.7 \pm 1.5$ years $)$, both groups experienced a similar decrease in $\mathrm{M}$ $\left(-0.2 \pm 0.3\right.$ vs $\left.-0.2 \pm 0.3 \mathrm{mg} \cdot \mathrm{kg} \mathrm{EMBS}-1 \cdot \mathrm{min}^{-1}\right)$ but unlike in subjects who remained NGT, mean s.c. abd. AS did not increase further in subjects who transitioned to IGT (Fig. 2).

\section{Discussion}

While numerous cross-sectional studies have firmly established an association between the average size of s.c. abd. adipocytes and various metabolic abnormalities of obesity [8-14], is the first our study in Pima Indians to show prospectively that enlarged s. c. abd. adipocytes predicts the development of Type II diabetes. Although enlarged mean s. c. abd. AS was associated with insulin resistance in cross-sectional analyses, prospectively both abnormalities were independent and additive risk factors for diabetes. In response to long-term weight gain, insulin sensitivity decreased in direct proportion to an increase in mean s.c. abd. AS. Subjects who developed IGT, however, were characterized by enlarged s.c. abd. AS at baseline and, in response to weight gain, experienced no further increase in mean s.c. abd. AS. Together, these findings indicate that the presence of enlarged s.c. abd. adipocytes predisposes people with NGT to Type II diabetes through mechanisms that seem to be in part related to and in part independent of insulin resistance. 

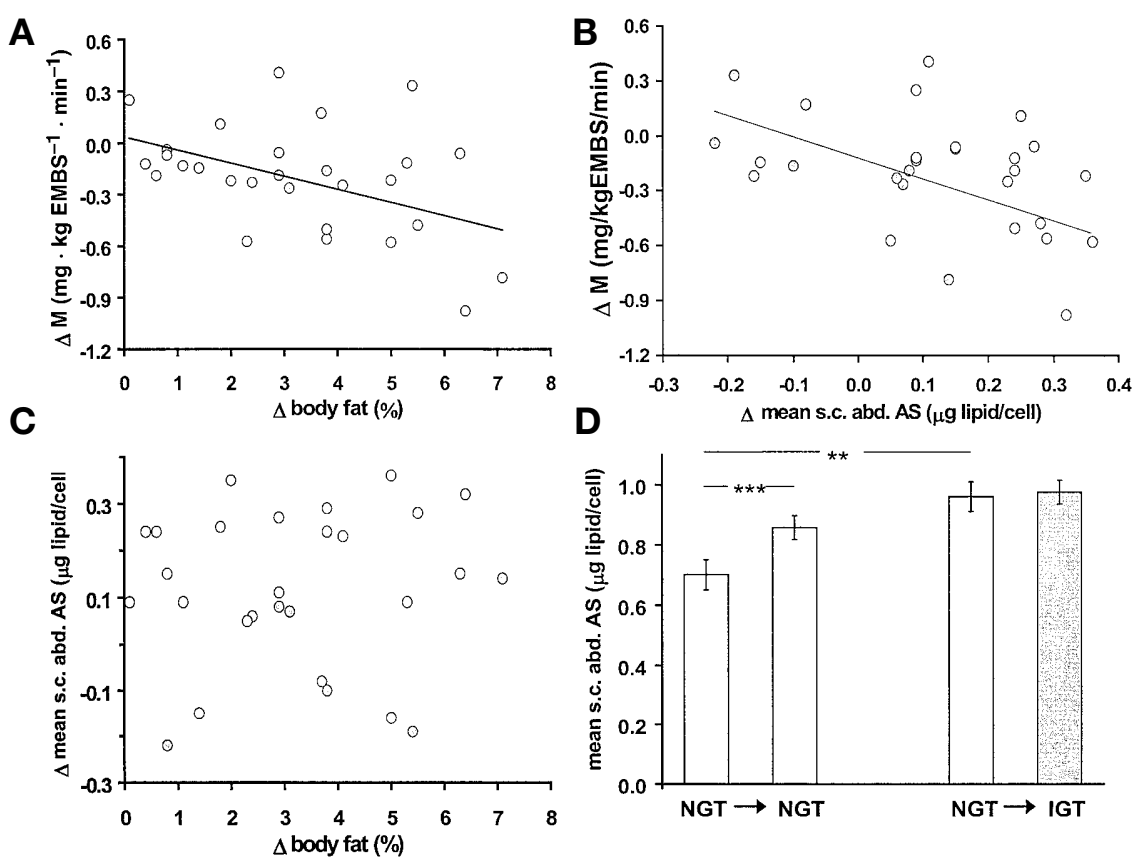

Fig. 2 A-D. Longitudinal analysis. Changes $(\Delta)$ in insulinstimulated glucose disposal $(\mathrm{M})$ in relation to changes in per cent body fat $(\mathbf{A}, r=-0.43, p<0.03)$ and changes in mean s.c. abd. AS ( $\mathbf{B}, r=-0.44, p<0.02)$ in 28 Pima Indians with initially NGT who gained an average of $7.7 \mathrm{~kg}$ body weight over $2.7 \pm 1.3$ years and either remained $\operatorname{NGT}(n=20, \bigcirc)$ or developed IGT $(n=8,0)$. C Changes in mean s.c. abd. AS were not related to changes in per cent body fat., $r=0.09$, NS. D In subjects who remained NGT, fat gain was associated with an increase in mean s.c. abd. AS (*** $p<0.001$ vs baseline). In subjects who developed IGT, mean s.c. abd. AS was higher at baseline ( $p<0.01$ vs non-progressors) and did not increase further with weight gain

The cross-sectional finding of a curvilinear positive relation between mean s.c. abd. AS and per cent body fat confirms previous findings $[9,12,18]$ but also shows that at any given degree of adiposity, there is substantial interindividual variation in mean s.c. abd. AS. Most of the subjects with IGT and diabetes fell above the regression line and accordingly, had, on average, larger s.c. abd. adipocytes than those with NGT, even after accounting for differences in adiposity. Previous findings of a close relation between mean s.c. abd. AS and fasting insulin concentrations $[8,9,12,13]$ and of enlarged s. c. abd. adipocytes in people with GH deficiency [25] and polycystic ovary syndrome [26] suggested that this is in part attributable to insulin resistance. This notion was confirmed in our study, in which the rate of insulinstimulated glucose disposal (M), as directly measured by the hyperinsulinaemic clamp technique, was inversely correlated with mean s. c. abd. AS, even after adjusting for adiposity. These cross-sectional results cannot establish whether enlarged s.c. abd. adipo-

cytes are a cause or a consequence of insulin resistance or glucose intolerance, however.

Our prospective finding that enlarged s.c. abd. AS predicted the development of Type II diabetes in subjects with NGT over an average follow-up of 9 years was therefore important, establishing that in people who develop diabetes, enlargement of s. c. abd. adipocytes is detectable well before the onset of hyperglycaemia, when glucose tolerance is still normal. Another important, and somewhat unexpected, finding was that the predictive effect of enlarged s. c. abd. AS was independent of the predictive effect of insulin resistance and also of low early phase insulin secretion, two previously identified predictors of diabetes in Pima Indians [6]. The risk ratio for enlarged s. c. abd. AS with and without $\mathrm{M}$ in the prediction model was 5.8 and 8.5 , respectively, suggesting that only about one-third of the predictive effect of enlarged s. c. abd. AS was attributable to its association with insulin resistance. It should be noted that this does not necessarily mean that the remaining predictive effect of enlarged s.c. abd. AS is mediated by mechanisms other than insulin resistance and insulin secretory dysfunction. It is possible, for instance, that enlarged s. c. abd. adipocytes predispose to the subsequent development of either insulin resistance or insulin secretory dysfunction or both which then in turn lead to impairments in glucose tolerance. Although additional analyses of our dataset showed no predictive effect of enlarged s. c. abd. AS on subsequent changes in M or AIR (data not shown), the limited number of subjects and relatively short follow-up duration in those analyses prevent us from ruling out this possibility altogether.

The repetition of fat biopsies and hyperinsulinaemic clamps at follow-up in some of the study participants allowed us also to examine how changes in 
mean s.c. abd. AS relate to changes in overall adiposity, insulin sensitivity and glucose tolerance in response to long-term weight gain. The results of this longitudinal analysis show that changes in $M$ with weight gain were inversely and independently related to changes in both mean s.c. abd. AS and per cent body fat. It is noteworthy that changes in mean s.c. abd. AS were not related to changes in per cent body fat in this small number of subjects and that in some, weight gain was accompanied by a decrease rather than an increase in mean s.c. abd. AS. Stratification of the subjects according to their glucose tolerance status at follow-up showed that although, on average, mean s.c. abd. AS increased in subjects who maintained NGT, subjects who developed IGT had larger mean s. c. abd. AS at baseline and experienced no further increase with weight gain, despite a similar decrease in insulin sensitivity. This is consistent with our prospective finding that enlarged s.c. abd. AS precedes the development of glucose intolerance.

Given that insulin resistance and insulin secretory dysfunction are the two major defects underlying the development of Type II diabetes [5, 29, 38, 39] and assuming that the predictive effect of enlarged s. c. abd. AS must ultimately be mediated by either one or both of these abnormalities, the question arises by which mechanisms this might occur. There are at least two conceivable models.

The first possibility is that enlarged s. c. abd. adipocytes do not have pathophysiological significance by themselves but are instead simply a manifestation (end-organ response) of another, as yet unknown pathogenic factor that independently leads to enlarged mean s.c. abd. AS, insulin resistance, and worsening of glucose tolerance. Glucocorticoids, for example, which in excess lead to insulin resistance and glucose intolerance, are known to stimulate preadipocyte differentiation [40] and lipoprotein lipase activity [41] thereby possibly affecting adipocyte size [42]. Similarly, sex steroids and GH/IGF-1 also could affect both glucose homeostasis and adipocyte size [24-26, 43, 44]. Unfortunately, plasma concentrations of these hormones were not measured in our study. Hyperinsulinaemia also has an anabolic effect on adipose tissue and can cause insulin resistance [45]. In rodents, destruction of the ventromedial hypothalamus leads to a syndrome of vagally mediated insulin hypersecretion that is associated with insulin resistance and increased adipocyte size; both abnormalities are reversed after reduction of insulin hypersecretion by vagotomy [46]. Previous findings that Pima Indian children have larger s. c. abd. adipocytes [33] and higher plasma concentrations of insulin and pancreatic polypeptide (a surrogate marker of vagal pancreatic tone) [47] than Caucasian children and that fasting hyperinsulinaemia predicts diabetes independent of insulin resistance in Pima Indian adults [30] suggest that primary (possibly vagally mediated) insulin hypersecretion could be an early abnormality in the pathogenesis of diabetes in this population. The relatively small number of subjects in the present prospective analysis prevents us from distinguishing the separate predictive effects of fasting hyperinsulinaemia and mean s. c. abd. AS on diabetes risk.

The other possible explanation for the association between mean s.c. abd. AS and diabetes risk is that enlarged adipocytes themselves have a pathogenic role.

For instance, enlarged adipocytes express and probably secrete increased amounts of leptin, TNF $\alpha$ and IL-6 [15, 48-50], all of which have been implicated in the pathogenesis of insulin resistance and Type II diabetes. Whether these or perhaps other, as yet unknown, adipocyte-derived factors contribute to our present observations remains to be seen.

It is also known that enlarged adipocytes have increased lipolytic activity [51]. Some authors have suggested that increased lipolysis leads to increased NEFA turnover and oxidation, which in turn could lead to increased hepatic glucose production and insulin resistance through the Randle cycle, respectively $[52,53]$. Notwithstanding these basic pathways, it should be noted that in vitro measurements of adipocyte lipolysis cannot be used to predict systemic NEFA metabolism in vivo [54]. Studies in Pima Indians indicate that the exponential increase in adipocyte lipolysis with increasing adiposity is not accompanied by a similar increase in whole-body NEFA turnover and oxidation [54]. Further arguing against increased lipolysis as the major pathogenic effect of enlarged adipocytes are our present findings that basal adipocyte lipolysis, although positively correlated with mean s.c. abd. AS, could neither explain the cross-sectional association between mean s.c. abd. AS and M, nor the predictive effect of enlarged s.c. abd. AS on diabetes. Although we have previously reported that high fasting plasma NEFA concentrations predict diabetes in Pima Indians [55], the predictive effect of NEFA in that study was lost after adjusting for mean s.c. abd. AS, again suggesting that the predictive effect of enlarged s.c. abd. AS is not simply attributable to abnormal NEFA release.

A notable third mechanism that could explain our results has recently emerged with the finding that $\operatorname{PPAR} \gamma$ agonists, which stimulate preadipocyte differentiation, improve insulin sensitivity in parallel with a reduction in mean s.c. AS in rodents [15, 56]. Based on these and other findings, it has been suggested by some authors ([57] and N. Grant, personal communication) that an impaired ability to differentiate new fat cells, possibly manifested as an enlargement of existing ones, might have a causal role in the development of Type II diabetes. According to this hypothesis, failure to differentiate new adipocytes compromises the capacity for lipid storage in adipose tissue which in turn lead to increased fat accumula- 
tion in other tissues such as visceral fat, skeletal muscle, liver and perhaps pancreatic beta cells [57]. Although there is growing evidence that abnormal fat accumulation in non-adipose tissues is an important in bringing about both insulin resistance and insulin secretory dysfunction (the lipotoxicity theory, [59, $60]$ ), the mechanisms underlying this abnormal partitioning of lipids are probably more complex than simply an "overflow" of fat from filled adipocytes. The average size of s.c. adipocytes from other regions of the body such as the femorogluteal sites, is much smaller and apparently not related to insulin sensitivity and glucose tolerance $[8,9]$. Nevertheless, recent findings that the transgenic ablation of white adipose tissue in mice causes a syndrome of severe insulin resistance and glucose intolerance associated with pronounced steatosis of skeletal muscle and liver [61], and that these abnormalities can be largely reversed by implantation of adipose tissue [62] point to a critical role of adipose tissue and lipid storage in the pathogenesis of Type II diabetes.

Acknowledgements. The authors wish to thank the members and leaders of the Gila River Indian Community for their continuing cooperation. We are also indebted to Drs. S. Lillioja and B. Howard for their contributions to the study and to Dr. E. Danforth Jr. and N. Grant for stimulating discussions. We gratefully acknowledge the nursing and dietary staff of the Clinical Research Unit for the care of the subjects and the Clinical Diabetes and Nutrition Section technical staff for assisting in the analyses.

\section{References}

1. Colditz GA, Willett WC, Stampfer MJ et al. (1990) Weight as a risk factor for clinical diabetes in women. Am J Epidemiol 132: 501-513

2. Knowler WC, Pettitt DJ, Saad MF, Bennett PH (1990) Diabetes mellitus in the Pima Indians: incidence risk factors and pathogenesis. Diabetes Metab Rev 6: 1-27

3. Chan JM, Rimm EB, Colditz GA, Stapfer MJ, Willett WC (1994) Obesity, fat distribution, and weight gain as risk factors for clinical diabetes in men. Diabetes Care 17: 961-969

4. Ohlson LD, Larsson B, Svardsudd K et al. (1985) The influence of body fat distribution on the incidence of type 2 diabetes mellitus: 13.5 years of follow-up of the participants of the study of men born in 1913. Diabetes 34: 1055-1058

5. Lillioja S, Mott DM, Spraul M et al. (1993) Insulin resistance and insulin secretory dysfunction as pre-cursors of non-insulin dependent diabetes mellitus. Prospective studies of Pima Indians. N Engl J Med 329: 1988-1992

6. Vague J (1956) The degree of masculine differentiation of obesities: a factor determining predisposition to diabetes, atherosclerosis, gout, and uric calculus disease. Am J Clin Nutr 4: 20-27

7. Zamboni M, Armellini F, Cominacini L et al. (1994) Obesity and regional body fat distribution in men: separate and joint relationships to glucose tolerance and plasma lipoproteins. Am J Clin Nutr 60: 682-683

8. Kissebah AH, Vydelingum N, Murray R et al. (1981) Relation of body fat distribution to metabolic complications of obesity. J Clin Endocrinol Metab 54: 254-260
9. Krotkiewski M, Bjorntorp P, Sjostrom L, Smith U (1983) Impact of obesity on metabolism in men and women: importance of regional adipose tissue distribution. J Clin Invest 72 : $1150-1162$

10. Salans LB, Knittle JL, Hirsch J (1968) Role of adipose cell size and adipose tissue insulin sensitivity in the carbohydrate intolerance of human obesity. J Clin Invest 47: 153-165

11. Hirsch J, Knittel JL (1970) Cellularity of obese and nonobese human adipose tissue. Fed Proc 29: 1516-1521

12. Stern JS, Batchelor BR, Hollander N, Cohn CK, Hirsch J (1972) Adipose cell size and immunoreactive insulin levels in obese and normal weight adults. Lancet ii: 948-951

13. Brook CG, Lloyd JK (1973) Adipose cell size and glucose tolerance in obese children and effect of diet. Arch Dis Child 48: 301-304

14. Salans LB, Cushman SW, Weismann RE (1973) Studies of human adipose tissue: adipose cell size and number in nonobese and obese patients. J Clin Invest 52: 929-941

15. Okuno A, Tamemoto H, Tobe K et al. (1998) Troglitazone increases the number of small adipocytes without the change of white adipose tissue mass in obese Zucker rats. J Clin Invest 101: 1354-1361

16. Kubota N, Terauchi Y, Miki H et al. (1999) PPAR $\gamma$ mediates high-fat diet induced adipocyte hypertrophy and insulin resistance. Mol Cell 4: 597-607

17. Bloch C, Clemons P, Sperling M (1989) Puberty decreases insulin sensitivity. J Pediatr 110: 481-487

18. Knittle JL, Timmers K, Ginsberg-Fellner F, Brown RE, Katz DP (1979) The growth of adipose tissue in children and adolescents: cross sectional and longitudinal studies of adipose cell number and size. J Clin Invest 63: 239-246

19. Greenwood MR, Hirsch J (1974) Postnatal development of adipocyte cellularity in the normal rat. J Lipid Res 15: 474-483

20. Andersen O, Kuhl C (1988) Adipocyte insulin receptor binding and lipogenesis at term in normal pregnancy. Eur J Clin Invest 18: 575-581

21. Steingrimsdottir L, Greenwood MR, Brasel JA (1980) The effect of pregnancy, lactation, and a high fat diet on adipose tissue in Osborne-Mendel rats. J Nutr 110: 600-609

22. Kohrt WM, Kirwan JP, Staten MA, Bourey RE, King DS, Holloszy JO (1993) Insulin resistance in aging is related to abdominal obesity. Diabetes 42: 273-281

23. Morin CL, Gayles EC, Podolin DA, Wei Y, Xu M, Pagliassotti MJ (1998) Adipose tissue-derived tumor necrosis factor activity correlates with fat cell size but not insulin action in aging rats. Endocrinology 139: 4998-5005

24. Hew FL, Koschmann M, Christopher M et al. (1996) Insulin resistance in growth hormone-deficient adults: defects in glucose utilization and glycogen synthase activity. J Clin Endocrinol Metab 81: 555-564

25. Bonnet F, Vanderschueren-Lodeweyckx M, Eeckels R et al. (1974) Subcutaneous adipose tissue and lipids in blood in growth hormone deficiency before and after treatment with growth hormone. Pediatr Res 8: 800-805

26. Dunaif A, Segal KA, Shelley DR, Green G, Dobrjansky A, Licholai T (1992) Evidence for distinctive and intrinsic defects in insulin action in polycystic ovary syndrome. Diabetes 41: 1257-1266

27. Hanefeld M, Schneider H, Haller H (1972) Human adipocyte volumes: maximum size, and correlation to weight index in maturity-onset-diabetes. Diabetologia 8: 287-291

28. Bjorntorp P, Jonsson A, Berchthold P (1972) Adipose tissue cellularity in maturity-onset diabetes mellitus. Acta Med Scand 191: 129-132 
29. Weyer C, Bogardus C, Mott DM, Pratley RE (1999) The natural history of insulin secretory dysfunction and insulin resistance in the pathogenesis of type 2 diabetes mellitus. J Clin Invest 104: 787-794

30. Weyer C, Hanson R, Tataranni PA, Bogardus C, Pratley RE (2000) A high fasting plasma insulin concentrations predicts type 2 diabetes independent of insulin resistance: evidence for a pathogenic role of relative hyperinsulinemia. Diabetes 49: 2094-2101

31. World Health Organization (1985) Diabetes mellitus: Report of a WHO study group. WHO Technical Report Series No 727, World Health Organization, Geneva

32. American Diabetes Association (1998) Report of an expert committee on the diagnosis and classification of diabetes mellitus (Committee Report). Diabetes Care 21 [Suppl 1]: S5-S19

33. Abbott WG, Foley JE (1987) Comparison of body composition, adipocyte size, and glucose and insulin concentrations in Pima Indian and Caucasian children. Metabolism 36: $576-579$

34. Foley JE, Lillioja S, Zawadzki J, Reaven GM (1986) Comparison of glucose metabolism in adipocytes from Pima Indians and Caucasians. Metabolism 35: 193-195

35. Kashiwagi A, Mott DM, Bogardus C, Lillioja S, Reaven GM, Foley JE (1985) The effect of short-term overfeeding on adipocyte metabolism in Pima Indians. Metabolism 34: 364-370

36. Kashiwagi A, Verso MA, Andrews J, Vasquez B, Reavan GM, Foley JE (1983) In vitro insulin resistance of human adipocytes isolated from subjects with noninsulin-dependent diabetes mellitus. J Clin Invest 72: 1246-1254

37. Miles J, Glassoch R, Aiken J, Gerich J, Haymond A (1983) A microfluorimetric method for the determination of free fatty acids. J Lipid Res 24: 95-99

38. Ferrannini E (1998) Insulin resistance vs. insulin deficiency in non-insulin dependent diabetes mellitus: problems and prospects. Endocr Rev 19: 477-490

39. Gerich JE (1998) The genetic basis of type 2 diabetes mellitus: impaired insulin secretion versus impaired insulin sensitivity. Endocr Rev 19: 491-503

40. Hauner H, Entenmann G, Wabitsch M et al. (1989) Promoting effects of glucocorticoids on the differentiation of human preadipocyte precursor cells. J Clin Invest 84: 1663-1670

41. Ottoson M, Vikman-Adolfsoon K, Enerback S, Olivecrona G, Bjorntorp P (1994) The effects of cortisol on the regulation of lipoprotein lipase activity in human adipose tissue. J Clin Endocrinol Metab 79: 820-825

42. Krotkiewski M, Blohme B, Lindholm N, Bjorntorp P (1976) The effects of adrenal glucocorticoids on regional adipocyte size in man. J Clin Endocrinol Metab 42: 91-97

43. Wabitsch M, Heinze E (1993) Body fat in GH-deficient children and the effect of treatment. Horm Res 40: 5-9

44. Elbers JM, de Jonge S, Teerlink T, Asscheman H, Seidell J, Gooren LJ (1999) Changes in fat cell size and in vitro lipolytic activity of abdominal and gluteal adipocytes after one-year cross-sex hormone administration in transsexuals. Metabolism 48: 1371-1377
45. Del Prato S, Leonetti E, Simonson DC, Sheehan P, Matsuda M, DeFronzo RA (1994) Effect of sustained physiological hyperinsulinaemia and hyperglycaemia on insulin secretion and insulin sensitivity in man. Diabetologia 37: $1025-1035$

46. Jeanrenaud B (1978) Hyperinsulinaemia in obesity syndromes: its metabolic consequences and possible etiology. Metabolism 27: 1881-1892

47. Weyer C, Salbe AD, Lindsay R, Bogardus C, Pratley RE, Tataranni PA (2001) Exaggerated pancreatic polypeptide secretion in Pima Indians: can increased parasympathetic drive to the pancreas contribute to hyperinsulinemia and diabetes in humans? Metabolism, in press.

48. Mohammed-Ali V, Pinkey JH, Coppack SW (1998) Adipose tissue as an endocrine and paracrine organ. Int $\mathbf{J}$ Obes 22: $1145-1158$

49. Oberkofler H, Beer A, Breban D, Hell E, Krempler F, Patsch W (1997) Human obese gene expression: alternative splicing of mRNA and relation to adipose tissue localization. Obes Surg 7: 390-396

50. Fried SK, Bunkin DA, Greenberg AS (1998) Omental and subcutaneous adipose tissues of obese subjects release interleukin-6: depot difference and regulation by glucocorticoid. J Clin Endocrinol Metab 83: 847-850

51. Foley JE, Anderson RC, Bell PA et al. (1997) Pharmacological strategies for reduction of lipid availability. Ann NY Acad Sci 827: 231-245

52. Ferranini E, Barrett EJ, Bevilaqua S, DeFronzo RA (1983) Effect of fatty acids on glucose production and utilization in man. J Clin Invest 72: 1737-1747

53. Randle PJ, Hales CN, Garland PB, Newsholme EA (1963) The glucose-fatty acid cycle. Its role in insulin insensitivity and the metabolic disturbances in diabetes mellitus. Lancet i: $785-789$

54. Lillioja S, Foley JE, Bogardus C, Mott DM, Howard BV (1986) Free-fatty acid metabolism and obesity in man: in vivo and in vitro comparisons. Metabolism 35: 505-514

55. Paolisso G, Tataranni PA, Foley JE, Bogardus C, Howard BV, Ravussin E (1995) A high concentration of fasting plasma non-esterified fatty acids is a risk factor for the development of NIDDM. Diabetologia 38: 1213-1217

56. Spiegelman BM (1998) PPAR-gamma: adipogenic regulator and thiazolidinedione receptor. Diabetes 47: 507-514

57. Danforth E Jr (2000) Failure of adipocyte differentiation causes type 2 diabetes mellitus? (letter). Nat Med 26: 13

58. Reference deleted

59. Higa M, Zhou YT, Ravazzola M, Baetens D, Orci L, Unger RH (1999) Troglitazone prevents mitochondrial alterations, $\beta$-cell destruction, and diabetes in obese prediabetic rats. Proc Natl Acad Sci USA 96: 11513-11518

60. McGarry JD, Dobbins RL (1999) Fatty acids, lipotoxicity and insulin secretion. Diabetologia 42: 128-138

61. Moitra J, Mason MM, Olive M et al. (1998) Life without white fat: a transgenic mouse. Genes Dev 12: 3175-3180

62. Gavrilova O, Marcus Samuels B, Graham D et al. (2000) Surgical implantation of adipose tissue reverses diabetes in lipoatrophic mice. J Clin Invest 105: 271-278 